\title{
Eficacia de los mecanismos jurídicos para la protección de los derechos de las comunidades negras vulnerados por la actividad minera: el caso del municipio de Río Quito, Chocó
}

\author{
Escolástica del Rosario Mosquera Caro" \\ Lisneider Hinestroza Cuesta***
}

Recibido: 30 de agosto de 2016 • Aprobado: 27 de septiembre de 2017

https://doi.org/10.22395/ojum.v17n33a10

\section{RESUMEN}

El marco jurídico colombiano permite el desarrollo de la actividad minera en territorios de comunidades negras como es el caso del municipio de Río Quito situado en el departamento del Chocó. En este artículo se presenta una investigación de carácter descriptivo sobre la vulneración de los derechos de las comunidades negras por la actividad minera en el municipio de Río Quito, las cuales por mandato constitucional cuentan con diversos mecanismos jurídicos que le permiten la protección de sus derechos como la acción popular, la acción de grupo y la acción de tutela de forma excepcional. En el 2008 el ejercicio de la actividad minera realizada de forma ilegal en Río Quito generó la contaminación de las aguas con tóxicos como mercurio, aceite combustible para motores y aceites lubricantes, colocando en alto riesgo la existencia de sus habitantes, al afectar con ello la salud, la vida y el entorno cultural.

Palabras clave: Comunidades negras; derechos colectivos fundamentales; grupos étnicos; actividad minera.

Artículo científico producto del proyecto de investigación titulado Estudio jurídico para la selección de instrumentos legales que protejan y restablezcan los derechos colectivos vulnerados por la extracción de minerales en el municipio de Río Quito en el departamento del Chocó. Grupo de investigación Derecho, Sociedad y Medio Ambiente de la Universidad Tecnológica de Chocó "Diego Luis Córdoba". Financiado por el Departamento Administrativo de Ciencia Tecnología e Innovación (Colciencias) y la Gobernación del Chocó a través de la Fundación para la Educación y el Desarrollo Social (FES), mediante el Programa Jóvenes Investigadores-Modalidad tradicional. Convocatoria para la formación de capital humano de alto nivel para el departamento del Chocó N. ${ }^{\circ}$ 694. Avances de la investigación se presentaron en la ponencia oral La acción de tutela como mecanismo transitorio de protección de derechos colectivos vulnerados por la extracción ilícita de minerales en el municipio de Río Quito, Chocó, en el marco del VI Congreso Internacional de Derecho "Democracia y Conflictos Sociales en América Latina", realizado en la ciudad de Manizales (Colombia) del 12 al 14 de agosto de 2015.

** Abogada de la Universidad Tecnológica del Chocó "Diego Luis Córdoba" . Joven Investigadora del grupo de investigación Derecho Sociedad y Medio Ambiente en la Universidad Tecnológica del Chocó (Colombia). Correo electrónico: rosario-91-sagrado@hotmail.com. Orcid: https://orcid.org/0000-0002-5889-0013

** Abogada de la Universidad Tecnológica del Chocó "Diego Luis Córdoba" (Colombia). Magíster en Derecho de los Recursos Naturales de la Universidad Externado de Colombia (Bogotá). Estudiante de Doctorado en Derecho de la Universidad Externado de Colombia (Bogotá). Líder del grupo de investigación Derecho Sociedad y Medio Ambiente en la Universidad Tecnológica del Chocó "Diego Luis Córdoba" (Colombia). Docente asistente en Comisión de Estudio de la Universidad Tecnológica del Chocó "Diego Luis Córdoba" (Colombia). Correo electrónico: lisneider@yahoo.es. Orcid: orcid.org/0000-0003-3580-1716 


\title{
Effectiveness of legal mechanisms to protect the rights of black communities harmed by mining activities in the municipality of Río Quito-Chocó
}

\begin{abstract}
Colombia's legal framework allows the development of mining activities in territories of black communities such as the municipality of Rio Quito located in the department of Choco. This article presents a descriptive investigation about the violation of the rights of the black communities by the mining activity in the municipality of Río Quito, which by constitutional mandate has various legal mechanisms that allow the protection of their rights as popular action, group action and tutelage action exceptionally. In 2008, the mining activity carried out illegally in Río Quito generated water pollution with toxic substances such as mercury, motor oil and lubricating oils, putting the existence of its inhabitants at high risk, thereby affecting health, life and the cultural environment.
\end{abstract}

Keywords: Black communities, fundamental collective rights, ethnic groups, mining activity.

\section{Eficácia dos mecanismos jurídicos para a proteção dos direitos das comunidades negras vulnerabilizadas pela atividade mineira: o caso do município de Río Quito, Chocó}

\begin{abstract}
RESUMO
O contexto jurídico colombiano permite o desenvolvimento da atividade mineira em territórios de comunidades negras, como é o caso do município de Río Quito, situado no estado de Chocó. Neste artigo, apresenta-se uma pesquisa de caráter descritivo sobre a violação dos direitos das comunidades negras por causa da atividade mineira no município de Río Quito. Tais comunidades contam, por mandato constitucional, com diversos mecanismos jurídicos que permitem a proteção de seus direitos, como a ação popular, a ação de grupo e a ação de tutela de forma excepcional. Em 2008, o exercício da atividade mineira realizada de forma ilegal em Río Quito gerou a contaminação das águas com tóxicos como mercúrio, óleo combustível para motores e óleos lubrificantes, o que colocou a existência de seus habitantes em alto risco ao afetar com isso a saúde, a vida e o entorno cultural.
\end{abstract}

Palavras-chave: Atividade mineira; comunidades negras; direitos coletivos fundamentais; grupos étnicos 


\section{INTRODUCCIÓN}

La Comisión Interamericana de Derechos Humanos (CIDH), a través del informe "Pueblos indígenas, comunidades afrodescendientes y recursos naturales: protección de derechos humanos en el contexto de actividades de extracción, explotación y desarrollo", exhorta a las actividades extractivas implementadas en los territorios ocupados históricamente por los pueblos indígenas y las comunidades afrodescendientes, áreas que albergan una gran cantidad de recursos naturales y reconoce la importancia que tales emprendimientos pueden tener para la prosperidad y el desarrollo económico de los países de América. Sin embargo, el desarrollo económico de los Estados miembros no puede realizarse en detrimento de sus obligaciones fundamentales de respetar y garantizar derechos humanos (Comisión Interamericana de Derechos Humanos, 2015).

En tal sentido, la Constitución Política de 1991 apunta a un modelo de desarrollo sostenible, en el que la actividad productiva debe guiarse por los principios de conservación, restauración y sustitución; por lo tanto, el Estado colombiano permite el aprovechamiento de los recursos naturales, siempre y cuando con ello no se cause perjuicios en términos de salubridad individual o social, como tampoco daño o deterioro que atente contra la diversidad e integridad del ambiente (Corte Constitucional, 2013, Sentencia T-154).

De igual forma, la actividad minera en Colombia se encuentra consagrada en el Código de Minas, Ley 685 de 2001, la cual define la minería como el conjunto de actividades que relacionan el descubrimiento, exploración y explotación de yacimientos minerales; que son la acumulación natural de sustancia mineral o fósil, utilizable como materia prima o como fuente de energía, que se encuentra en el subsuelo o en la superficie terrestre y cuyo volumen es tal que puede ser explotado con fines económicos.

De acuerdo con el informe preventivo sobre los alcances de la minería ilegal en Colombia, presentado por la Procuraduría General de la Nación, lo que se pretende con esta actividad minera en el país, es lograr un equilibrio armónico entre desarrollo económico y gasto de la oferta ambiental, siempre y cuando se garantice la protección de los derechos colectivos. Por ende, el Estado colombiano cuenta con instrumentos legales que posibilitan la protección de los derechos colectivos vulnerados por el ejercicio de la minería ilegal (Procuraduría General de la Nación, 2011).

Así las cosas, la actividad minera es la principal fuente de economía del departamento del Chocó ubicado en la región pacífica de Colombia, donde la extracción se concentra especialmente en la explotación de metales preciosos como el oro, de la cual depende para el sustento familiar buena parte de la población de manera directa e indirecta. De esta forma, las políticas, planes de desarrollo y formas de vida de los habitantes están profundamente marcadas por dicha actividad (Moya, 2016). 
Sin embargo, teniendo en cuenta lo expuesto por la Contraloría General del Departamento del Chocó en el Informe anual del estado de los recursos naturales y del medio ambiente en el departamento del Chocó, esta actividad es realizada generalmente de forma ilegal en más de 17 municipios del departamento, generando destrucción de suelos, contaminación de fuentes hídricas, perdida de la biodiversidad y desarraigo de las comunidades asentadas en el territorio, lo que conlleva a una situación alarmante de degradación ambiental, producto de la omisión por parte de autoridades competentes encargadas de ejercer el control y vigilancia por la extracción de minerales en el territorio chocoano (Contraloría General del Departamento del Chocó, 2012).

En este sentido, la minería es una de las actividades económicas responsable de la vulneración de derechos colectivos en territorios de comunidades negras, como es el caso del municipio de Río Quito, situado en el departamento del Chocó, (Alcaldía de Rio Quito, 2002), donde la extracción de minerales es realizada generalmente de forma ilegal, lo que imposibilita la implementación de planes de manejo que consideren medidas de prevención, mitigación y corrección de la degradación ambiental (Contraloría General del Departamento del Chocó, 2012).

Evidentemente, es claro que el Estado colombiano ha previsto los instrumentos especiales para la defensa de los derechos colectivos, fundamentalmente la acción popular, consagrada en la Constitución Política de 1991 y regulada por la Ley
472 de 1998; esta se ejerce para evitar el daño contingente, hacer cesar el peligro, la amenaza, la vulneración o agravio sobre los derechos e intereses colectivos, o restituir las cosas a su estado anterior cuando fuere posible; por otro lado, se encuentran las acciones de grupo, establecidas en el artículo 88 de la Constitución de Colombia, la acción de cumplimiento y excepcionalmente la acción de tutela; esta última se ejerce particularmente cuando existe conexidad directa entre la violación de derechos colectivos y la vulneración de derechos fundamentales, como es el caso, del derecho a la vida y a la salud (Mesa, 2010).

Teniendo en cuenta todo lo expuesto, cabe preguntarse: ¿Cuáles son los derechos colectivos vulnerados a las comunidades negras del municipio de Río Quito por la extracción de minerales en relación con la eficacia de los mecanismos jurídicos empleados para la protección de estos derechos? En ese orden de ideas, para responder a esta pregunta, se abordan aspectos relevantes como son: 1) El municipio de Río Quito, un espacio de convivencia entre la ocupación ancestral y la minería ilegal; 2) Análisis del marco normativo para el aprovechamiento, exploración y explotación de minerales en territorios de grupos étnicos en Colombia; 3) Procesos que se han adelantado sobre aprovechamiento, exploración o explotación ilícita de recursos minerales en el municipio de Rio Quito durante el período comprendido entre el 2010-2014; 4) Títulos mineros otorgados en el municipio de Rio Quito durante el período comprendido entre el 2010-2014; 5) Derechos colectivos 
vulnerados a las comunidades negras del municipio de Rio Quito por la extracción de minerales y 6) Conclusiones.

Para adelantar esta investigación se recurrió al método descriptivo (Ruiz, 2007), y la investigación se desarrolló en tres etapas: 1) la revisión bibliográfica relacionada con la normativa que regula los derechos colectivos en Colombia y de igual forma, la normativa que regula el desarrollo de la actividad minera; 2) la recolección de información, en esta fase se presentaron peticiones de información a entidades que tienen algún tipo de función frente al otorgamiento de títulos mineros, permisos ambientales, inspección, vigilancia y control, como son: Agencia Nacional de Minería (oficio radicado $\mathrm{N}^{\circ}$ 20159120001331) del 9 de junio de 2015, Corporación Autónoma Regional para el Desarrollo Sostenible del Chocó (Codechocó) (oficio radicado N. ․ 2015-2-1547) del 9 de junio de 2015, Alcaldía Municipal de Río Quito (oficio enviado el 14 de diciembre de 2015), Defensoría del Pueblo (oficio radicado $\mathrm{N}^{\circ}$ 6013-513) del 16 de junio de 2015, la Fiscalía Quinta Promiscua Seccional Quibdó-Chocó, Procuraduría Judicial para asuntos Ambientales (oficio radicado $\mathrm{N}^{\circ}{ }^{2}$ 20150210001972) del 3 de junio de 2015, al Instituto Colombiano para el Desarrollo Rural (Incoder) (oficio radicado $\mathrm{N}^{\circ}$ 00203) del 25 de mayo de 2015 y a los Consejos Comunitarios de San Isidro, Villa Conto y Paimadó (oficios enviados el 19 de junio de 2015); De igual forma, se realizaron entrevistas semiestructuradas a los representantes legales de estos 3 Consejos, (L. Romaña, comunicación personal, 4 de diciembre de 2015),
(V. Chaverra, comunicación personal, 14 de diciembre de 2015) y (N. Cabrera, comunicación personal, 26 de noviembre de 2015); y por último 3) el análisis y la consolidación de la información.

\section{EL MUNICIPIO DE RIOO QUITO, UN ESPACIO DE CONVIVENCIA ENTRE LA OCUPACIÓN ANCESTRAL Y LA MINERÍA ILEGAL}

El municipio de Río Quito se encuentra localizado a los $5^{\circ} 25^{\prime}$ de latitud norte y $76^{\circ} 40^{\prime}$ de longitud este, respecto al meridiano de Greenwich, con una altura promedio de 45 metros sobre el nivel del mar; limita por el norte con el municipio de Quibdó; por el sur, con el municipio del Cantón de San Pablo y Cértegui; por el oriente, con el municipio de Atrato, y por el occidente, con el municipio del Alto Baudó (Alcaldía de Río Quito, 2002) tal y como se encuentra referenciado el grafico $\mathrm{N} .{ }^{\circ} 1$.

Este municipio tiene una extensión de 70 kilómetros cuadrados, de los cuales $60.966 \mathrm{~m}^{2}$ corresponden a las comunidades negras y 9034 a los resguardos indígenas, con una temperatura promedio que oscila entre $26^{\circ}$ y $27^{\circ} \mathrm{C}$ (Alcaldía de Río Quito, 2002).

Fue creado mediante Ordenanza 004 del 25 de abril de 1999. Río Quito se caracteriza por poseer grandes cantidades de selvas vírgenes en las que abundan especies silvestres como la guagua (agouti paca), tatabro (pecari tajacu) y armadillo (dasypus nove). De igual forma, Río Quito goza de una gran variedad de especies de árboles madereros como abarco (cariniana pyriformis), 
Gráfico N.․ 1. Localización geográfica del municipio de Río Quito respecto al departamento del Chocó y Colombia

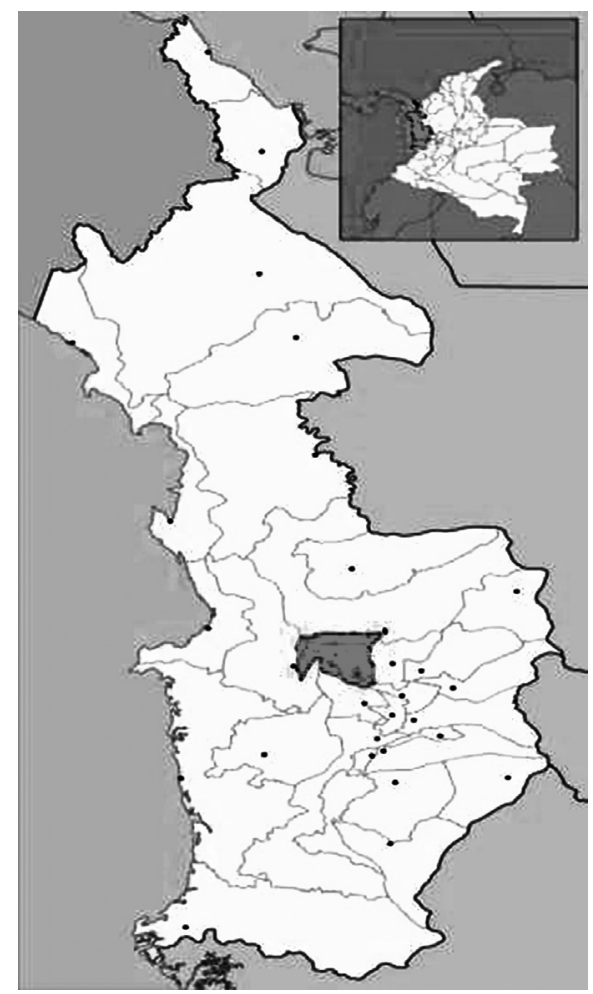

Fuente: Alcaldía de Rio Quito, 2002

lirio (iris germánica), cedro (cedrela odorata) y diferentes peces de aguas dulce. La minería, la agricultura, la pesca y la explotación maderera son las principales fuentes de ocupación de sus habitantes (Alcaldía Municipal de Río Quito, 2015).

Asimismo, posee recursos naturales que potencian el desarrollo en el lugar, como es el caso del sector minero, que comprende la existencia de metales preciosos como el oro y el platino, los cuales se encuentran diseminados en las vertientes de los ríos, pero la falta de control y vigilancia por parte de las autoridades competentes propicia una extracción y aprovechamiento no racional de los minerales, generando pérdida de la biodiversidad en el territorio (Alcaldía de Río Quito, 2012). Por otro lado, el municipio de Río Quito fue catalogado como el pueblo más pobre de Colombia según lo expuesto por el Departamento Administrativo Nacional de Estadística (DANE) en el 2005, en el que los habitantes viven con el $98 \%$ de sus necesidades básicas insatisfechas (Cuevas, 2015).

Este municipio se encuentra dividido en 8 corregimientos y 4 resguardos indígenas. 
Tabla 1. Relación de corregimientos y resguardos indígenas ubicados en el municipio de Río Quito-Chocó

\begin{tabular}{|l|l|}
\hline \multicolumn{1}{|c|}{ Corregimientos } & \multicolumn{1}{c|}{ Resguardos indígenas } \\
\hline Paimadó (Cabecera municipal) & Miasa de Partadó \\
\hline Tuadó & Pato y Gengadó \\
\hline San Isidro & San José Amia Pato \\
\hline La Soledad & Lomitas de Curundo \\
\hline Villa Conto & \\
\hline Boca de Apartadó & \\
\hline Chiguarandó Alto & \\
\hline La Punta Antadó & \\
\hline
\end{tabular}

Fuente: Alcaldía de Río Quito, 2002

En cuanto al desarrollo de la actividad minera en el municipio de Río Quito, esta se ha venido realizado de forma ilegal en los últimos años, por lo que se han presentado diversas quejas por parte de sus habitantes respecto a los severos impactos ambientales que se causan sobre los recursos naturales y del ambiente, razón por la cual, el acalde ordenó, por medio del Decreto 027 de 2008, suspender la explotación minera ilícita que se realiza con dragas de succión o dragones y cual quier tipo de maquinaria pesada en jurisdicción del municipio (Alcaldía Municipal de Río Quito, 2008), donde la extracción de oro ilegal representa un 98,3\% y el 1,7\% corresponde a la minería artesanal ${ }^{1}$ (El Espectador, 2016).

1 La Corte Constitucional considera que la que minería artesanal consiste en la explotación de depósitos minerales a pequeña escala, en la que se utilizan métodos manuales transmitidos de generación en generación o con ayuda de equipos muy sencillos, por lo general elaborados por los mismos mineros, para la extracción de los metales. Esta es la clase de minería conocida como minería
El líder comunitario Venancio Chaverra explica que antes de la minería mecanizada el río era cristalino, saludable, de aguas claras, y que las poblaciones se dedicaban a la pesca, a la agricultura y a la minería artesanal y de estas actividades emanaba la subsistencia y la vida cultural. Añade que el señor Mosquera (chocoano, minero del bajo Cauca) y sus socios extranjeros descubrieron el potencial minero del río Quito en 1997; a partir de entonces comenzó un proceso de minería masiva y las dragas poblaron el río en busca de oro. Recuerda que la explotación inició en el Cantón de San Pablo. Hoy la mayoría de minería mecanizada o de succión se realiza en río Quito y en Cantón de San Pablo, desplazando toda actividad agrícola y pesquera. Sostiene que la situación es caótica porque lo poco que se logra pescar está contaminado

de subsistencia, que realizan las comunidades étnicas y los campesinos desde hace siglos (Corte Constitucional, 2016, Sentencia T-622). 
con mercurio y la gente de la región no compra ni consume pescado del río por temor a enfermarse. También denuncia la extinción de peces como la "Boquiancha y el veringo" (Corte Constitucional, 2016, Sentencia T-622).

Asimismo, en el 2008 la explotación minera ilegal de metales preciosos en Río Quito generó la contaminación de las aguas con tóxicos como mercurio, aceite combustible para motores y aceites lubricantes, lo que puso en alto riesgo la existencia de los habitantes del lugar, al afectar con ello la salud, la vida y el entorno cultural (Alcaldía Municipal de Río Quito, 2008).

En ese sentido, teniendo en cuenta un estudio realizado por la Universidad de Cartagena, buena parte de la población del municipio de Río Quito se encuentra contaminada por el uso del mercurio, lo que afecta gravemente la salud de sus habitantes, quienes no cuentan con los centros médicos adecuados para atender satisfactoriamente las diferentes enfermedades que se presentan por el desarrollo de la minería ilegal, motivo por el cual, deben trasladarse a otras ciudades del país para recibir la atención médica pertinente (Hernández, 2016).

Por otro lado, los trabajos de explotación minera se realizan sin que haya control por parte de la autoridad competente, y han dejado efectos irreversibles, ocasionando alteraciones radicales del paisaje, destrucción del suelo y del bosque natural, destrucción de cultivos de pancoger, pérdida del ecosistema etiológico por efecto del mercurio ${ }^{2}$ utilizado y erosión de las orillas (Contraloría General de la Republica, 2014).

De igual modo, la Defensoría del Pueblo, en respuesta a oficio radicado $N^{\circ}{ }^{6} 6013$ 513 del 16 de junio de 2015, manifestó que la actividad minera en el municipio de Río Quito se está desarrollando de forma clandestina violando el derecho a la consulta previa; además, el uso desaforado de insumos químicos como el cianuro y el mercurio 3 ha generado graves conflictos

2 El mercurio es un metal que se caracteriza por ser líquido inodoro a temperatura ambiente y se volatiliza fácilmente. En la región de América Latina y el Caribe (ALC) se ha utilizado principalmente para la extracción de oro y plata desde la antigüedad. Una vez que el mercurio ingresa al ambiente como contaminante, es sumamente nocivo. Los daños a la salud humana incluyen alteraciones permanentes en el sistema nervioso, y en particular al sistema nervioso en desarrollo. Debido a ello, y al hecho de que el mercurio puede ser transferido de una madre a su hijo durante el embarazo, los bebés, niños y mujeres embarazadas, son considerados las poblaciones más vulnerables (Centro Coordinador Convenio Basilea \& Centro Regional Convenio de Estocolmo para América Latina y el Caribe, 2014).

3 En cuanto al uso del mercurio, se considera que Colombia es el país con más contaminación por mercurio en América. De acuerdo con estudios de la Organización Mercury Watch en el 2016, se calcula que el país emite 180 toneladas anuales de mercurio en la extracción artesanal de oro, lo que constituye un importante riesgo para la protección ambiental y la salud humana de sus habitantes. Por tanto, el estado ha expedido la Ley 1658 de 2013 destinada a regular el uso, la comercialización, el manejo, el transporte, el almacenamiento, la disposición final y la liberación al ambiente del mercurio en las actividades industriales. Esta Ley establece un plazo de 5 años para erradicar el uso del mercurio en el sector minero. Sin embargo, hasta el momento existe una gran debilidad institucional para controlar el uso del mercurio en la explotación del oro, en zonas como el departamento del Chocó, debido a que las Corporaciones Autónomas Regionales no realizan 
socio-ambientales y una altísima degradación de los ecosistemas (Defensoría del Pueblo, 2015).

Al respecto, el Alcalde de Rio Quito expresa que, aunque ha tomado las medidas necesarias para suspender el desarrollo de la actividad minera que se realiza de forma ilegal en su municipio, dicha actividad continúa causando grandes daños a la población, por lo tanto, considera que para lograr un control efectivo de la minería ilegal en el municipio de Rio Quito, se requiere de la intervención del Estado nacional colombiano a largo plazo (Hernández, 2016).

\section{ANÁLISIS DEL MARCO NORMATIVO PARA EL APROVECHAMIENTO, EXPLORACIÓN Y EXPLOTACIÓN DE MINERALES EN TERRITORIOS DE GRUPOS ÉTNICOS EN COLOMBIA}

Desde la perspectiva del Sistema Interamericano, los Estados miembros tienen la obligación esencial de implementar un marco normativo adecuado para la pro tección de los derechos humanos frente a actividades extractivas, de explotación y desarrollo en territorios de comunidades indígenas y afrodescendientes. Esta obligación incluye el deber de prevenir violaciones a los derechos humanos, el cual exige la identificación previa y el seguimiento adecuado de los impactos que generaría determinado plan o proyecto en los derechos humanos de las poblaciones afectadas por el mismo, tanto antes de la

los monitoreos correspondientes para establecer las concentraciones de mercurio en el agua (Rojas y Montes, 2016). autorización u otorgamiento de permisos, como durante la implementación del proyecto. Igualmente, la Comisión se refiere al deber de prevenir actividades ilegales y formas de violencia contra la población en zonas afectadas por actividades extractivas, de explotación y desarrollo (Comisión Interamericana de Derechos Humanos, 2015).

Ahora bien, en Colombia la actividad minera se encuentra regulada por la Ley 685 de 2001, por la cual se expide el Código de Minas y se dictan otras disposiciones, este Código tiene como objeto, teniendo en cuenta lo estipulado en su artículo 1, fomentar la exploración técnica y la explotación de los recursos mineros de propiedad estatal y privada, así como también, estimular estas actividades con el propósito de satisfacer los requerimientos de la demanda interna y externa de los mismos, en aras a que su aprovechamiento se realice de forma armónica, teniendo en cuenta los principios y normas de explotación racional de los recursos naturales no renovables y del ambiente, generando de esta forma un desarrollo sostenible.

Igualmente, consagra en su artículo 14 que únicamente se podrá constituir, declarar y probar el derecho a explorar y explotar minas de propiedad estatal, mediante el contrato de concesión minera, debidamente otorgado, e inscrito en el Registro Minero Nacional. Por otro lado, consagra en su artículo 160 que el aprovechamiento ilícito de recursos mineros consiste en el beneficio, comercio o adquisición a cualquier título, de minerales 
extraídos de áreas no amparadas por un título minero.

Por consiguiente, los alcaldes efectuarán el decomiso provisional de los minerales que se transporten o comercien y que no se hallen amparados por factura o constancia de las minas de donde provengan. Así, si se comprobare la procedencia ilícita de los minerales se pondrán, además, a disposición de la autoridad penal que conozca de los hechos. Lo dispuesto en este artículo no se aplicará a la minería de barequeo ${ }^{4}$ teniendo en cuenta lo consagrado en el artículo 161.

Por último, es importante resaltar que la responsabilidad de denunciar los hechos constitutivos de la actividad minera realizada de forma ilícita recaen sobre cualquier persona que tenga conocimiento del aprovechamiento, exploración o explotación ilícita de minerales, quien deberá dar aviso al alcalde del lugar y este, previa comprobación de la situación denunciada, procederá al decomiso de los minerales extraídos y, por consiguiente, deberá poner los hechos en conocimiento de la autoridad minera, sin perjuicio de las acciones penales correspondientes, tal como lo estipula la ley citada en su artículo 164.

4 El artículo 155 de la Ley 685 de 2001 consagra al barequeo como la actividad popular de los habitantes de terrenos aluviales actuales, que consiste en el lavado de arenas por medios manuales sin ninguna ayuda de maquinaria o medios mecánicos y con el objeto de separar y recoger metales preciosos contenidos en dichas arenas (Congreso de la Republica, 2001).
Por otra parte, teniendo en cuenta lo expuesto en el informe preventivo sobre los alcances de la minería ilegal en Colombia, presentado por la Procuraduría General de la Nación. La licencia ambiental es el control estatal por excelencia sobre los recursos naturales renovables, y frente a las explotaciones mineras advierte, que para su solicitud debe anexarse el respectivo título minero, por lo cual, la autoridad no podría otorgar una licencia ambiental para una explotación de minería ilegal, lo que no quiere decir que estas queden exentas y fuera del alcance de la discrecionalidad de la ley, pues les permite a las autoridades ambientales la posibilidad de utilizar mecanismos de control accesorios o sustitutos como son los planes de manejo ambiental' ${ }^{5}$ Sin embargo, el plan de manejo ambiental es un control posterior a la ejecución de los proyectos y no previo como lo es la licencia ambiental (Procuraduría General de la Nación, 2011).

Del análisis normativo, se puede inferir que las normas establecidas por el Estado colombiano para el aprovechamiento, exploración y explotación de minerales en territorios de grupos étnicos no cumplen a cabalidad con los reglamentos estipulados por la Comisión Interamericana de Derechos Humanos, en relación con la obligación de prevenir y realizar el seguimiento adecuado de los impactos que puede genera un proyecto en los derechos humanos de una población, ya que permite la utilización de mecanismos sustitutos, como un plan de manejo ambiental cuando no se cumple con el requisito del

Ver artículo 4 del Decreto 2820 de 2010 (República de Colombia, 2010). 
título minero para la obtención de la licencia ambiental; por tanto, no se realiza un control previo como lo hace la licencia ambiental, sino que, por el contrario se estaría realizando un control posterior al desarrollo del proyecto, lo que propicia la vulneración de derechos.

\section{PROCESOS PENALES QUE SE HAN ADELANTADO POR EL APROVECHAMIENTO, EXPLORACIÓN O EXPLOTACIÓN ILÍCITA DE RECURSOS MINERALES EN EL MUNICIPIO DE RIOO QUITO ENTRE LOS AÑOS 2010-2014}

La investigación arrojó que se han adelantado en el despacho de la Fiscalía Octava Seccional Quibdó, desde el año 2010 a 2014, ocho (8) procesos sobre daño en los recursos naturales, cuatro (4) procesos sobre explotación ilícita de yacimiento minero y otros materiales. Vale la pena resaltar que actualmente de los 12 procesos que se encuentran activos en etapa de indagación, no existen condenados por estos hechos, en virtud a que no se encuentran plenamente identificados e individualizados los responsables (Fiscalía Octava Seccional Quibdó-Chocó, 2015). (Ver tabla 3).

Tras labores de inteligencia lideradas por la Unidad contra Minería y el Terrorismo de la Policía Nacional, Ejército Nacional, Fuerza Aérea, Armada Nacional, y con acompañamiento de Fiscalía General y Procuraduría Judicial, Ambiental y Agraria, en Río Quito (Chocó) se hallaron 25 dragones (estructuras flotantes de dos pisos) utilizados por bandas criminales y un mismo número de maquinaria pesa- da como retroexcavadora con el que se practicaba minería ilegal. En la operación participaron más de 100 uniformados especializados, quienes llegaron a los campamentos mineros ubicados en PaimadóRío Quito en más de 10 helicópteros. En este operativo no se realizaron capturas; sin embargo, de acuerdo con las cifras del MinAmbiente, en el 2016 se realizaron más de 6200 capturas por delitos ambientales en todo el país (El Tiempo, 2017).

Ahora bien, teniendo en cuenta lo estipulado por la Comisión Interamericana de Derechos Humanos en el informe "Pueblos indígenas, comunidades afrodescendientes y recursos naturales: protección de derechos humanos en el contexto de actividades de extracción, explotación y desarrollo" los Estados miembros tienen el deber de prevenir actividades ilegales y formas de violencia contra la población en zonas afectadas por actividades extractivas, de explotación y desarrollo (Comisión Interamericana de Derechos Humanos, 2015). Así, todos los procesos penales que se han adelantado por el aprovechamiento, exploración o explotación ilícita de recursos minerales en el municipio de Río Quito en los últimos años representan el esfuerzo por parte del Estado colombiano para cumplir dicha obligación.

\section{TÍTULOS MINEROS OTORGADOS EN EL MUNICIPIO DE RÍO QUITO ENTRE EL 2010-2014}

El gráfico $N^{\circ}{ }^{\circ}$, muestra que se encuentran ocho (8) títulos mineros (contratos de concesión) en estado vigente de ejecución en el municipio de Río Quito. 
Tabla 2. Relación de procesos que se han adelantado en la Fiscalía Octava Seccional Quibdó, sobre aprovechamiento, exploración o explotación ilícita de recursos minerales.

\begin{tabular}{|c|c|l|l|}
\hline N. $^{\circ}$ & Número del proceso & \multicolumn{1}{|c|}{ Delito } & $\begin{array}{c}\text { Estado del } \\
\text { proceso }\end{array}$ \\
\hline 1 & 270016001100201401288 & Daño en los recursos naturales artículo 331 C. P. & Indagación \\
\hline 2 & 270016001100201303397 & Daño en los recursos naturales artículo 331 C. P. & Indagación \\
\hline 3 & 270016001100201302469 & Daño en los recursos naturales artículo 331 C. P. & Indagación \\
\hline 4 & 270016001100201303410 & Daño en los recursos naturales artículo 331 C. P. & Indagación \\
\hline 5 & 270016001100201402439 & $\begin{array}{l}\text { Explotación ilícita de yacimiento minero artículo } \\
\text { 338 C. P. }\end{array}$ & Indagación \\
\hline 6 & 270016001100201303408 & Daño en los recursos naturales artículo 331 C. P. & Indagación \\
\hline 7 & 270016001100201401294 & $\begin{array}{l}\text { Explotación ilícita de yacimiento minero y otros } \\
\text { materialesartículo 338 C. P. }\end{array}$ & Indagación \\
\hline 8 & 270016001100201102633 & Daño en los recursos naturales artículo 331 C. P. & Indagación \\
\hline 9 & 270016001100201101035 & $\begin{array}{l}\text { Aprovechamiento Ilícito De Los Recursos Natu- } \\
\text { rales artículo 328 C. P. }\end{array}$ & Indagación \\
\hline 10 & 270016001100201101651 & Daño en los recursos naturales artículo 331 C. P. & Indagación \\
\hline 11 & 270016001100201101492 & $\begin{array}{l}\text { Explotación ilícita de yacimiento minero y otros } \\
\text { materialesartículo 338 C. P. }\end{array}$ & Indagación \\
\hline 12 & 270016001100201402587 & $\begin{array}{l}\text { Explotación ilícita de yacimiento minero y otros } \\
\text { materiales artículo 338 C. P. }\end{array}$ & Indagación \\
\hline 13 & 270016001100201402527 & Daño en los recursos naturales artículo 331 C. P. & Indagación \\
\hline
\end{tabular}

Fuente: Fiscalía Octava Seccional Quibdó, Chocó. Respuesta al derecho de petición radicado N. 20150210001972, 2015

Por otro lado, en la tabla 4 se evidencia que se encuentran diez (10) solicitudes de legalización, de las cuales, seis (6) están vigentes y cuatro (4) se encuentran archivadas.

Por último, respecto a la licencia de exploración, se encontró que existen dos, las cuales han sido rechazadas (Agencia Nacional de Minería, 2015).

En relación con los permisos ambientales otorgados para la explotación de minera- les en Río Quito, la Corporación Autónoma Regional para el Desarrollo Sostenible del Chocó (Codechocó), en respuesta a oficio con radicado N. ${ }^{\circ}$ 2015-2-1547 del 9 de junio de 2015, informó que en el municipio de Río Quito no se ha otorgado ningún permiso para la explotación de minerales, como tampoco autorización ambiental a empresas multinacionales; de igual forma, estableció que hasta el momento se han iniciado 21 procesos sancionatorios contra la minería ilegal en la cuenca de Rio Quito (Codechocó, 2015). 
Tabla 3. Relación de los títulos mineros (Contratos de Concesión) que se encuentran en el municipio de Río Quito

\begin{tabular}{|c|l|l|l|}
\hline N. & Fecha de radicación & Estado del expediente & \multicolumn{1}{c|}{ Titular } \\
\hline 1 & $02 / 06 / 2010$ & Vigente en ejecución & Consejo comunitario de Paimadó. \\
\hline 2 & $13 / 02 / 2012$ & Vigente en ejecución & Proyecto Coco Hondo S. A. S. \\
\hline 3 & $13 / 02 / 2012$ & Vigente en ejecución & Proyecto Coco Hondo S. A. S. \\
\hline 4 & $13 / 02 / 2012$ & Vigente en ejecución & Proyecto Coco Hondo S. A. S. \\
\hline 5 & $13 / 02 / 2012$ & Vigente en ejecución & Proyecto Coco Hondo S. A. S. \\
\hline 6 & $24 / 02 / 2012$ & Vigente en ejecución & Proyecto Coco Hondo S. A. S. \\
\hline 7 & $24 / 02 / 2012$ & Vigente en ejecución & Proyecto Coco Hondo S. A. S. \\
\hline 8 & $10 / 05 / 2013$ & Vigente en ejecución & Proyecto Coco Hondo S. A. S. \\
\hline
\end{tabular}

Fuente: Agencia Nacional de Minería. Respuesta a derecho de petición. Radicado N ․ 20159120001331, 2015

Tabla 4. Relación de las solicitudes de legalización

que se encuentran en el municipio de Río Quito, Chocó (Colombia).

\begin{tabular}{|c|l|l|l|}
\hline N. $^{\circ}$ & Fecha de radicación & Estado de la solicitud & \multicolumn{1}{|c|}{ Titulares } \\
\hline 1 & $20 / 03 / 2013$ & Vigente & (8180013268) Consejo Comunitario de Paimadó. \\
\hline 2 & $21 / 03 / 2013$ & Vigente & (8180013268) Consejo Comunitario de Paimadó. \\
\hline 3 & $10 / 05 / 2013$ & Vigente & (8180013268) Consejo Comunitario de Paimadó. \\
\hline 4 & $10 / 05 / 2013$ & Vigente & (8180013268) Consejo Comunitario de Paimadó. \\
\hline 5 & $10 / 05 / 2013$ & Vigente & (8180013268) Consejo Comunitario de Paimadó. \\
\hline 6 & $24 / 09 / 2004$ & Vigente & (8180013268) Consejo Comunitario de Paimadó. \\
\hline 7 & $27 / 09 / 2004$ & Archivada & (8180013268) Consejo Comunitario de Paimadó. \\
\hline 8 & $13 / 01 / 2011$ & Archivada & (8180013268) Consejo Comunitario de Paimadó. \\
\hline 9 & $17 / 01 / 2011$ & Archivada & (8180013268) Consejo Comunitario de Paimadó. \\
\hline 10 & $28 / 01 / 2011$ & Archivada & (8180013268) Consejo Comunitario de Paimadó. \\
\hline
\end{tabular}

Fuente: Agencia Nacional de Minería. Respuesta derecho de petición. Radicado N. 20159120001331, 2015

Tabla 5. Relación de las licencias de exploración que se encuentran en el municipio de Río Quito (Chocó, Colombia).

\begin{tabular}{|c|l|l|l|}
\hline N. $^{\circ}$ & \multicolumn{1}{|c|}{ Fecha de radicación } & \multicolumn{1}{|c|}{ Estado del expediente } & \multicolumn{1}{c|}{ Titulares } \\
\hline 1 & $28 / 12 / 1993$ & Rechazado & Roboam Jaramillo \\
\hline 2 & $15 / 06 / 1993$ & Rechazado & Víctor Emilio Mosquera \\
\hline
\end{tabular}

Fuente: Agencia Nacional de Minería. Respuesta derecho de petición. Radicado N. 20159120001331, 2015 
En cuanto a los entables mineros ubicados en el municipio objeto de estudio, la Alcaldía Municipal, en respuesta a oficio radicado el 14 de diciembre de 2015, dio a conocer que se encuentran aproximadamente 35 entables mineros, de los cuales no poseen información en lo que tiene que ver con su ubicación, propietarios y equipo de trabajo, ya que esta información es suministrada a los consejos comunitarios de cada comunidad; además, estos cambian de sitio con mucha frecuencia, en ocasiones no permanecen ni un mes en el mismo lugar (Alcaldía de Río Quito, 2016).

\section{CONSEJOS COMUNITARIOS UBICADOS EN EL MUNICIPIO DE RÍO QUITO}

La investigación arrojó que en el municipio de Río Quito se encuentran ubicados 3 consejos comunitarios: San Isidro, Paimadó y Villa Conto.

Teniendo en cuenta el análisis de la información recolectada, respecto de las entrevistas realizadas a los líderes de los consejos comunitarios de San Isidro, Villa Conto y Paimadó del municipio de Río Quito, la investigación arrojó que el conocimiento que estos poseen respecto de las normas que regulan la actividad minera en Colombia no es suficiente comparado con el nivel de responsabilidad que deberían asumir por la magnitud de las funciones asignadas como máximos administradores de los territorios titulados en los términos de la Ley 70 del 93 y el Decreto 1745 de 1995. Al respecto, el representante legal del Consejo Comunitario de Paimadó fue el único que especificó conocer la Ley 685 de 2001 "Por la cual se expide el Código de Minas y se dictan otras disposiciones" (L. Romaña, comunicación personal, 4 de diciembre de 2015, V. Chaverra, comunicación personal, 14 de diciembre de 2015, y N. Cabrera, comunicación personal, 26 de noviembre de 2015).

Estas comunidades contemplan en su reglamento interno el desarrollo de la actividad minera de forma artesanal; además, pretenden realizar una actividad minera tradicional, de barequeo, que no afecte el medio ambiente a gran escala. En eso coincidieron los representantes legales de los Consejos Comunitarios de San Isidro y Villa Conto.

Tabla 6. Relación de Consejos Comunitarios ubicados en el municipio de Río Quito (Chocó, Colombia)

\begin{tabular}{|l|l|l|l|}
\hline \multicolumn{1}{|c|}{ Consejo Comunitario } & \multicolumn{1}{|c|}{ Resolución } & \multicolumn{1}{c|}{ Área } & \multicolumn{1}{c|}{ Familia } \\
\hline San Isidro & 0157 de 09 de febrero de 1998 & $12851-6400$ & 206 \\
\hline Villa Conto & 0160 de 09 de febrero de 1998 & $29026-1319$ & 330 \\
\hline Paimadó & 2724 de 27 de diciembre de 2001 & $17264-2898$ & 316 \\
\hline
\end{tabular}


En cuanto al representante del Consejo Comunitario de Paimadó, este aclaró que anteriormente se estaba realizando en su comunidad la minería de forma artesanal, pero actualmente tienen contrato de concesión desde el 2009 (Minería semi-mecanizada) ${ }^{66}$, lo cual coincide con la respuesta que emitió la Agencia Nacional Minera respecto a los títulos mineros (Contratos de Concesión) que se encuentran en el municipio de Río Quito, donde se puede apreciar con claridad, que los miembros de este Consejo Comunitario pretenden desarrollar la minería a gran escala, como se ilustra en la gráfico N. ${ }^{\circ} 4$.

Igualmente, los miembros de los consejos comunitarios realizan acciones frente al desarrollo de esta actividad, tales como: ejercer seguimiento, elaborar informes periódicos y ejercer control y vigilancia; para ello cuentan con una organización, la cual, en el caso del Consejo Comunitario de San Isidro, es el Comité de Delimitación de Área Minera; de otro lado, el Consejo Comunitario de Paimadó cuenta con la Junta Directiva para realizar esta labor; para ello se reúnen entre 1 y 3 meses aproximadamente o en cualquier momento, siempre y cuando la situación lo amerite, o se presente la necesidad. Sin embargo, los miembros del Consejo

6 La minería semi-mecanizada se considera como una suerte de "modernización o tecnificación" de la minería artesanal, en la cual se incluyen adaptaciones de pequeños equipos como motobombas, elevadores hidráulicos y pequeñas dragas de succión que mejoran las condiciones de trabajo y rendimiento en la remoción de material aluvial. Este tipo de minería permite a los trabajadores realizar sus labores en un menor tiempo y con mayor eficacia (Corte Constitucional, 2016, Sentencia T-622).
Comunitario de Villa Conto no poseen un comité u organización, lo que puede generar un inconveniente a la hora de adelantar, de forma eficaz, las acciones frente al desarrollo de la actividad minera en su territorio.

\section{DERECHOS COLECTIVOS VULNERADOS A LAS COMUNIDADES NEGRAS DEL MUNICIPIO DE RÍO QUITO POR LA EXTRACCIÓN DE MINERALES}

La Defensoría del Pueblo, en respuesta a oficio radicado $N .^{\circ} 6013-513$ del 16 de junio de 2015, ha puesto en conocimiento de las autoridades competentes de ejercer control y vigilancia, el alto riesgo de contaminación ambiental al que se exponen los habitantes del municipio de Río Quito ${ }^{77}$ por el ejercicio de la actividad minera ilegal, que vulnera derechos fundamentales y derechos colectivos, como el derecho a la vida (artículo 11 de la C. P.), a la salud (artículo 49 de la C. P.) y el derecho a gozar de un ambiente sano (artículo 79 de la C. P.).

Por consiguiente, en el 2011 el Consejo Comunitario de Paimadó instauró la

\footnotetext{
Grueso, Coordinadora de la Oficina de la Organización de las Naciones Unidas (ONU) para asuntos étnicos, señala que las condiciones de contaminación del río han contribuido a la baja tasa de reproducción de peces y, con el tiempo, a su desaparición. Agrega que también han realizado seguimiento a las afectaciones de salud causadas por los vertimientos de grandes cantidades de mercurio en el agua del río para lograr la separación del oro de la arena y las rocas, y que una vez separado, lo queman a cielo abierto produciendo vapores que generan más contaminación y afectaciones cutáneas en los miembros de las comunidades y en las zonas de los Consejos Comunitarios de Cocomopoca y Cocomacia (Corte Constitucional, 2016, Sentencia T-622).
} 
acción popular que denunciaba la violación de los derechos colectivos al medio ambiente sano (artículo 79 de la C. P.), al equilibrio ecológico (artículo 4, numeral c de la Ley 472 de 1998) y a la seguridad y salubridad pública (artículo 4, numeral g de la Ley 472 de 1998) de esa y otras comunidades de Río Quito. Justamente, en la Sentencia del 19 de noviembre de 2015, radicación N. ${ }^{\circ}$ 25000-23-24-0002011-00655-01, el Tribunal Administrativo de Cundinamarca reconoció que las actividades de explotación minera ilegal sobre la cuenca del río Quito han degradado el medio ambiente, afectado negativamente la pesca y la agricultura que realizan las comunidades negras y puesto en alto riesgo la salud de quienes habitan a orillas de este importante cuerpo hídrico del Chocó. Toda esta situación es a raíz de la inacción de las instituciones del Estado del orden local y nacional.

Para atender la situación, el Tribunal Administrativo de Cundinamarca a través de la Sentencia del 19 de noviembre de 2015, radicación N. ${ }^{\circ}$ 25000-23-24-000 2011-00655-0, ordenó a Codechocó y al municipio de Río Quito que realicen e implementen, en los próximos seis meses, un proyecto integral y detallado que atienda la crisis ambiental. Dicho plan deberá ser revisado y aprobado por el Ministerio de Ambiente y Desarrollo Sostenible, por lo que se espera que la autoridad nacional, como las autoridades locales, respondan con celeridad y rigor a la sentencia y actúen diligentemente para comenzar a solucionar la crisis ambiental en la región (Tierra Digna, 2015a).
De otro lado, la Corte Constitucional en Sentencia T-622 de 2016, realizó una visita al municipio de Río Quito con el objetivo de constatar los daños causados por la minería ilegal al medio ambiente y a la salud de los habitantes del lugar; esto es considerado un gran avance puesto que es la primera vez que la Corte Constitucional envía a funcionarios a realizar una inspección a este municipio, lo que muestra el interés del Estado de una u otra forma para darle solución a la problemática que viven estas personas; sin embargo, teniendo en cuenta lo expresado por González, abogada de Tierra Digna, el reto que debe afrontar la Corte Constitucional es enorme, puesto que no es solo un asunto minero, sino también es un serio problema de seguridad alimentaria, de salud, de derechos étnicos y de amenazas a líderes comunitarios, por ende, la Corte debe ordenar la creación de un plan para que progresivamente se desmonte esa minería que amenaza los territorios colectivos (Silva, 2016).

Así las cosas, en marzo del 2016, se llevó a cabo una operación militar en el municipio de Río Quito entre los sectores de San Isidro y Cascajudo, en contra de la explotación ilegal de yacimientos mineros de oro, en la que se destruyeron tres máquinas excavadoras y tres dragas. En esta participó la Infantería de Marina, el Eje Temático de Protección de los Recursos Naturales de Fiscalías Nacionales y la Policía Nacional del Departamento del Chocó. Con esta acción se busca contribuir a la protección del medio ambiente y debilitar las finanzas de los grupos armados al margen de la ley, teniendo en cuenta lo 
expuesto por la Brigada Contra la Minería Ilegal del Ejercito Nacional (El Espectador, 2016). Sin embargo, es importante lograr también una protección de los derechos colectivos fundamentales de las personas que viven en este municipio, los cuales se están viendo afectados gravemente por el desarrollo de la minería ilegal.

En cuanto a la vulneración del derecho al medio ambiente sano en Río Quito, la Corte Constitucional constató que a lo largo del recorrido por el río Quito (afluente del Atrato), que incluyó los sectores de Quibdó, Soledad, Guayabalito, Loma de Barranca, San Isidro, Bocas de Paimadó, Lomas Pueblo Nuevo, río Pató, Villa Conto y Paimadó, la actividad desplegada por las máquinas usadas en minería (dragas, dragones y retroexcavadoras) está afectando seriamente el medio ambiente y las comunidades vecinas. En particular, se advierte desviación y grave deterioro del cauce del río por bancos de arena, brazos y entradas artificiales. En las mismas se advierte presencia permanente de dragas y dragones. De igual forma, registra la destrucción de la capa vegetal, destrucción de riberas, desviación de cauces, taponamiento de afluentes, remoción de tierra (arena y rocas), construcción de islas artificiales con retroexcavadoras (bancos de arena) que luego de la explotación quedan abandonadas. No hay evidencia del desarrollo de actividades de pesca o agricultura (Corte Constitucional, 2016, Sentencia T-622).

Ahora bien, en lo que respecta a la eficacia de las acciones populares interpuestas por miembros del municipio de Río Quito, estas pueden surtir efectos positivos para la defensa de los territorios y derechos colectivos; sin embargo, por los plazos que se toman los jueces para decidir y por el trámite que exige este tipo de demandas, las acciones populares poco a poco han perdido la efectividad para atender el nivel de los problemas de contaminación que afronta Colombia, debido a que cuando diseñaron estas acciones los problemas ambientales no eran tan urgentes, masivos y estructurales como lo son actualmente en el departamento del Chocó. Por ende, surge la necesidad por parte del Estado colombiano de revisar los mecanismos que se seleccionan para evaluar si estos resultan eficaces ante las amenazas (Tierra Digna, 2015b).

En ese orden de ideas, a pesar de los operativos realizados en años anteriores, dragas gigantescas de dos pisos, siguen deformando la rivera del Río Quito, en el departamento del Chocó. La maquinaria avaluada en unos 40 mil millones de pesos es usada en la minería ilegal, cuyos propietarios son brasileros expulsados de su país. Esta denuncia la realizó el senador Antonio Navarro Wolf, quien sobrevoló el Río Quito, encontrando un grave daño ambiental que contaría con la anuencia de los pobladores de la región. El congresista aseguró que mal contadas hay entre 50 y 60 dragas, avaluadas en unos 50 millones de pesos cada una. Por otro lado, recientemente, el Ministerio de Medio Ambiente, radicó un Proyecto de Ley para que Colombia ratifique el convenio internacional de Minamata como se le conoce al movimiento internacional de prohibición del uso de mercurio en la minería (Penagos, 2016). 
Así las cosas, el Estado se suscribió al Convenio de Minamata sobre Mercurio y su implementación en la región de América Latina y el Caribe, lo que representa la culminación de un esfuerzo conjunto de la comunidad internacional por enfrentar una problemática global que nos afecta a todos, pero muy particularmente a ciertos países de la región de América Latina y el Caribe. En ese sentido, el Gobierno colombiano está comprometido con la pronta entrada en vigor de este tratado internacional y su proceso de ratificación (Ministerio de Ambiente y Desarrollo Sostenible, 2017).

\section{CONCLUSIONES}

La actividad minera ilegal que se desarrolla en el municipio de Río Quito no solo ha generado graves daños al medio ambiente y pérdida de los ecosistemas, sino también la vulneración de derechos tanto colectivos como fundamentales de las comunidades negras que lo habitan, las cuales han instaurado las diferentes acciones que establece el Estado colombiano para la protección de estos derechos, como la acción popular y de grupo, que se encuentran consagradas en la Constitución Política de 1991 y en la Ley 472 de 1998; de igual forma, han interpuesto acciones de tutela, para proteger sus derechos colectivos fundamentales, como el derecho a la consulta previa; sin embargo, estos mecanismos jurídicos han resultado poco eficaces para salvaguardar los derechos de estas comunidades.

Por otro lado, la falta de control y vigilancia por parte de las autoridades com- petentes en el municipio de Río Quito propicia el desarrollo de la minería de forma ilícita, lo que genera un alto grado de degradación ambiental que, sumado al uso del mercurio, provoca graves problemas de salud en la población y perdida de los ecosistemas.

Por consiguiente, se requiere de la implementación de planes de manejo ambiental por parte de las autoridades competentes para controlar y erradicar el desarrollo de la actividad minera ilegal, que afecta el crecimiento económico del municipio y la salud de sus habitantes.

De igual forma, la suscripción del Convenio de Minamata sobre Mercurio y su implementación en la región de América Latina y el Caribe por parte de Colombia, como también la visita realizada por la Corte Constitucional al municipio de Río Quito se consideran avances significativos que reflejan el interese del Estado de implementar políticas que prohíban el uso del mercurio en la actividad minería.

\section{REFERENCIAS}

Alcaldía Municipal de Río Quito, (2008). Decreto 027 de 2008. Por medio del cual se suspende el aprovechamiento ilícito de recursos mineros en la Jurisdicción del Municipio del Río Quito-Chocó.

Alcaldía Municipal de Rio Quito. (2008). Decreto 038 de 2008. Por medio del cual se modifica el Decreto 035 del 19 de agosto de 2008, mediante el cual se declaró la calamidad pública en el Municipio de Río Quito Chocó, por contaminación de aguas, sedimentación y erosión. Rio Quito.

Alcaldía de Rio Quito. (2002). Plan de ordenamiento territorial. Recuperado el 10 de 
marzo de 2015 de http://cdim.esap.edu. co/BancoMedios/Documentos\%20PDF/ rioquitochocoeot2005-2016.pdf

Agencia Nacional de Minería. (2015). Títulos mineros que se han otorgado en el Municipio de Rio Quito y estado en el que se encuentran, durante el periodo comprendido entre el 2010-2014. Quibdó, Colombia: Punto de Atención Quibdó-ANM

Corte Constitucional de Colombia. Sentencia T-154 de 2013. Magistrado Ponente: Nilson Pinilla Pinilla. Colombia.

Corte Constitucional de Colombia. (2016). Sentencia T-622 de 2016. Magistrado Ponente: Jorge Iván Palacio Palacio. Colombia.

Comisión Interamericana de Derechos Humanos. (2015). Informe Pueblos indígenas, comunidades afrodescendientes y recursos naturales: protección de derechos humanos en el contexto de actividades de extracción, explotación y desarrollo. Recuperado el 20 de octubre de 2017 de http://www.oas. org/es/cidh/informes/pdfs/IndustriasExtractivas2016.pdf

Centro Coordinador Convenio Basilea y Centro Regional Convenio de Estocolmo para América Latina y el Caribe. (2014). El Convenio de Minamata sobre el Mercurio y su implementación en la región de América Latina y el Caribe. Recuperado el 24 de octubre de 2017 de http:// www.mercuryconvention.org/Portals/11/ documents/publications/informe _ Minamata _ LAC_ES_FINAL.pdf

Congreso de la Republica de Colombia. (2001). Ley 685 de 2001. Por la cual se expide el Código de Minas y se dictan otras disposiciones. Colombia.

Contraloría General del Departamento del Chocó. (2012) Informe anual sobre el estado de los recursos naturales $y$ del medio ambiente departamento del Chocó 2012. Recuperado el 3 de julio de 2015 de http://www.oas.org/es/cidh/informes/ pdfs/IndustriasExtractivas2016.pdf
Contraloría General del Departamento del Chocó. (2014) Informe de auditoría con enfoque regular Municipio de Rio Quito. p. 32. Recuperado el 1 de julio de 2015 de http://contraloriachoco.gov.co/sites/default/files/documentos/ Informe\%20Auditoria\%20Definitivo\%20 Rio\%20Quito.pdf

Cuevas, A. (2015). Río Quito, la vida fragmentada por la minería. El Espectador. Recuperado de http://www.elespectador.com/files/ especiales/rioquito6/index.html

Fiscalía Octava Seccional Quibdó-Choco. (2015). Procesos que se adelantan por aprovechamiento, exploración o explotación ilícita de recursos minerales en el municipio de Río Quito durante el periodo comprendido entre el 2010-2014. Quibdó, Colombia.

Henao, J. y González, A. (2016). La minería en el Chocó. En A. Moya (Ed). Minería y desarrollo Tomo IV: medio ambiente y desarrollo sostenible. 1ra ed. Bogotá, Colombia: Universidad Externado de Colombia.

Hernández, S. (05 de julio de 2016). Pobladores en Chocó, con mercurio de la minería en la sangre. El Espectador. Recuperado de http://www. eltiempo.com/colombia/otras-ciudades/ mineria-ilegal-en-el-choco/16637446

Medellín. (23 de febrero de 2017). Operativo a minería ilegal en Chocó evidenció grave daño ambiental. El Tiempo. Recuperado de http:// www.eltiempo.com/colombia/medellin/ operativo-a-mineria-ilegal-en-chocoevidencio-grave-dano-ambiental-61350

Mesa, G. (2010). Derechos ambientales en perspectiva de integralidad. (2a ed.). Bogotá, Colombia: Universidad Nacional de Colombia.

Ministerio de Ambiente y Desarrollo Sostenible. (2017). Convenio de Minamata. Bogotá, Colombia: Ministerio de Ambiente y Desarrollo Sostenible. Recuperado de http://www.minambiente.gov.co/index.php/ component/content/article/560-plantilla- 
254 Escolástica del Rosario Mosquera Caro • Lisneider Hinestroza Cuesta

asuntos-ambientales-y-sectorial-y-urbanasin-galeria-47

Penagos, A. (2016). La minería ilegal 'carcome' al Río Quito, en el Chocó. Prensa Senado. Bogotá, Colombia: Sendado. Recuperado de http://www. senado.gov.co/mision/item/25944-la-mineria-ilegal-\%E2\%80\%98carcome\%E2\%80\%99al-rio-quito-en-el-choco

Presidencia de la Republica de Colombia. (2010). Decreto 2820 de 2010. Por el cual se reglamenta el Título VIII de la Ley 99 de 1993 sobre licencias ambientales. Bogotá, Colombia.

Procuraduría General de la Nación. (2011). Informe preventivo sobre minería ilegal en Colombia. Recuperado el 17 de agosto de 2015 de https://www.procuraduria.gov.co/ portal/media/file/MINERIA\%20ILEGAL\%20 EN\%20COLOMBIA\%20\%20DOCUMENTO. $\underline{\mathrm{pdf}}$

Redacción Nacional. (14 de marzo de 2016). Duro golpe a la minería ilegal en el municipio de Río Quito, Chocó. El Espectador. Recuperado de http://www.elespectador.com/noticias/ nacional/duro-golpe-mineria-ilegal-elmunicipio-de-rio-quito-cho-articulo622174
Ruiz, R. (2006). Historia y evolución del pensamiento científico. Culiacán, México. Recuperado el 8 de septiembre de 2015 de http://www.eumed. net/libros-gratis/2007a/257/7.1.htm

Silva, S. (5 de febrero de 2016). Así fue la visita de la Corte Constitucional al municipio más pobre de Colombia. El Espectador. Recuperado de http://www.elespectador.com/noticias/ medio-ambiente/asi-fue-visita-de-corteconstitucional-al-municipio-mas-articulo-614824

Tierra Digna. (2015a). Sentencia reconoce la inacción del estado en la degradación ambiental de Rio Quito. Bogotá, Colombia: Tierra Digna. Recuperado de http://tierradigna.org/2015/12/10/ sentencia-reconoce-la-inaccion-del-estadoen-la-degradacion-ambiental-de-rio-quitochoco/

Tierra Digna. (2015b). Sentencia de Río Quito, una gota de esperanza para las comunidades y los ríos del Chocó. Bogotá, Colombia: Tierra Digna. Recuperado de https://redjusticiaambientalcolombia.files.wordpress.com/2015/12/ sentencia-de-rc3ado-quito _ _crc3b3nica. pdf 